\title{
A história do Basquetebol de Volta Redonda: uma possibilidade de contextualização dentro da Educação Física
}

\section{The history of basketball in Volta Redonda: a possibility of contextualization within Physical Education}

\author{
${ }^{1}$ Marcelo Dantas Britto mdbbritto@yahoo.com.br \\ ${ }^{2}$ Marcelo Paraíso Alves
}

\begin{abstract}
RESUMO
O presente artigo objetiva compreender as práticas pedagógicas dos professores de Educação Física da rede municipal de Volta Redonda, mais especificamente a maneira como desenvolvem os processos de ensino sobre a história do Basquetebol. O trabalho apresenta como proposta o resgate da trajetória histórica dos sujeitos que participaram da constituição do Basquetebol em Volta Redonda, década de 1950 e 1960 . A metodologia desenvolveu-se por intermédio de duas ações complementares: a revisão da literatura e da pesquisa de campo, por intermédio da aplicação de um questionário com perguntas abertas e fechadas a 32 professores da rede municipal de ensino de Volta Redonda. Os resultados apresentados no questionário aplicado aos profissionais de Educação Física demonstraram, que alguns só ensinam o que o conhecimento hegemônico proporciona. Eles justificam este posicionamento metodológico apontando para alguns fatores como a falta de conhecimento da modalidade ou a ausência de literaturas com informações mais específicas.
\end{abstract}

Palavras-chave: História, Basquetebol, Educação Física.

\begin{abstract}
This paper aimstounderstandthepedagogicalpracticesofthePhysicalEducationteachersfromthecityof Volta Redonda. More precisely, it sets as a goaltocomprehendthewaythosehavedevelopedtheteaching processes aboutthehistoryofthebasketball. The papersuggeststhe recall ofthehistorical path madebythosewhotookpartoftheconstitutionofthebasketball in thecityof Volta Redonda in the 1950sand 1960s. The methodologyhasbeendevelopedbytwocomplementaryactions: thereviewoftheliteratureandthefieldreview, byapplying a questionnairewith open andclosedquestionsto 32 teachersfromthe municipal educational system fromthecityof Volta Redonda. The resultspresented in thequestionnaireappliedtophysicaleducationprofessionalsdemonstratedthat some onlyteach whatthehegemonicknowledge provides. They justify this methodo logical position pointing to some factors such as lack of knowledge of thes portor the lack of literature with more specific information.
\end{abstract}

Keywords: Historical, Basketball, Physical Education.

1 Professor Universitário e Ensino Fundamental.

2 Professor de Ensino Superior e Ensino Fundamental e Médio, UniFOA/IFRJ. 


\section{INTRODUÇÃO}

A disciplina Educação Física emerge no final do século XIX marcada por uma concepção anátomo-fisiológica em que se priorizava a constituição de uma pessoa forte, robusta, limpa, habilidosa, performática Soares (2002). Em decorrência desse objetivo, a formação dos profissionais deste campo do conhecimento, no processo de longa duração, também sofreu a interferência de tal concepção.

Não fugindo a esse processo, a formação dos professores na década de 1970, sofreu a influência do contexto sócio-histórico era influenciado diretamente pela ditadura militar. Se no campo da Educação, no período citado, a intervenção do pensamento técnico-burocrático criou o que se convencionou denominar de Tecnicismo (Tendência Pedagógica da Educação Brasileira), na área da Educação Física a tendência que serviu como referência no processo de formação de professores foi o Competitivismo (CASTELANI FILHO, 2011).

É importante salientar que tanto o Tecnicismo quanto o Competitivismo, buscavam a eficiência, a eficácia, a produtividade, a memorização, como conceitos basilares das ações pedagógicas realizadas. Especificamente, com relação ao professor de Educação Física, buscava-se no processo de seleção de candidatos, por intermédio do teste de aptidão física, os mais aptos, fortes saudáveis e habilidosos.

Assim, cabe ressaltar que este contexto social, político, econômico e cultural influenciou o processo de formação docente no referido período e, segundo Vago (2009), ainda influencia as práticas pedagógicas dos docentes da referida área.

Diante do exposto cabe perguntar: como se desenvolve o processo de ensino e aprendizagem da história do Basquetebol nas escolas municipais de Volta Redonda? Qual a relação das práticas esportivas locais com os fatos e acontecimentos ligados ao Basquetebol? Até que ponto o professor de Educação Física ao trabalhar com o conteúdo de Basquetebol, valoriza as práticas esportivas realizadas historicamente em âmbito local?

É importante ressaltar que desde a década de 1980 diversos estudiosos (COLETIVO DE AUTORES, 1992) buscaram outras perspectivas para repensar possíveis caminhos que pudessem levar a um desprendimento da visão do conservadorismo, que até o momento, incorporava a ação dos profissionais de educação física. Neste período, a referida área, começava a direcionar um pensamento crítico para mudanças, ampliações e aprofundamentos, que pudessem aproximar-se de uma maior contribuição para a cultura corporal.

Bracht (1999, p. 78) menciona que as discussões desenvolvidas no “campo da pedagogia, sobre o caráter reprodutor da escola e sobre as possibilidades de sua contribuição para uma transformação radical da sociedade capitalista, foi absorvida pela Educação Física”.

No intuito de entender um pouco mais sobre tal concepção, precisamos compreender que a Educação Física na atualidade tem uma gama de propostas pedagógicas bem diversificadas, mas que sofreu influências históricas inclusive com características advindas da aptidão física e esportiva. Muitos profissionais não exploram ou não possuem conhecimento de tais propostas pedagógicas da área e, ainda vislumbram uma Educação Física promotora de grandes resultados dentro de competições.

Assim, o objetivo caminhou no sentido de investigar os pressupostos teóricos da racionalidade moderna e suas expressões para a Educação Física Escolar, mais especificamente para o ensino do Basquetebol nas escolas municipais de Volta Redonda. Cabe ressaltar que esta pesquisa emerge de uma pesquisa de mestrado e influenciou diretamente na criar um material didático em formato de DVD - O Basquetebol de Volta Redonda: uma história para ser recontada e re-conhecida -, com perfil de um documentário, contendo aspectos históricos do Basquetebol em Volta Redonda a ser disseminado na disciplina de Educação Física na Educação Básica. 


\section{METODOLOGIA}

A metodologia utilizada neste trabalho desenvolveu-se por intermédio de duas ações complementares: Primeiramente fez-se um estudo de campo fundado em uma abordagem de cunho qualitativo. Essa ação exigiu o entretecimento da revisão da literatura.

Para Minayo (2010), por sua importância, o trabalho de campo deve ser realizado a partir de referenciais teóricos, para posteriormente realizar-se a articulação ou leitura dos dados empíricos. Nesse sentido, buscou-se, com este procedimento metodológico atingir o objetivo inicial do trabalho, investigar o paradigma moderno e o ensino da Educação Física no Brasil.

A segunda ação se desenvolveu na direção do objetivo de investigar o ensino do Basquetebol nas escolas, da rede municipal de ensino de Volta Redonda. O procedimento utilizado foi o questionário com perguntas abertas e fechadas para professores da rede municipal de ensino de Volta Redonda. Cabe frisar que a rede municipal de Volta Redonda, possuía, no período da pesquisa, 50 professores de Educação Física e os questionários foram aplicados a 32 professores. O questionário foi submetido ao comitê de ética do Centro Universitário de Volta Redonda, sendo este liberado para sua aplicação.

A estratégia de utilização de um questionário com perguntas abertas e fechadas teve como proposta a ampliação de coleta de dados, já que perguntas fechadas, por serem padronizadas e de fácil aplicação, se tornam fáceis de codificar e, complementando o questionário, as perguntas abertas possibilitam recolher informações mais ricas, pois permite respostas mais livres e variadas dos fatos investigados (CERVO; BERVIAN, 2002).

\section{RACIONALIDADE MODERNA E A VALORIZAÇÃO DA RAZÃO: O DESPERDÍCIO DA EXPERIÊNCIA}

A racionalidade moderna emerge na sociedade atual privilegiando uma única forma de saber: o conhecimento científico, a história hegemônica, a escrita por um especialista, dentre outras formas padronizadas (SANTOS, 2002).

Para o autor, essa racionalidade emerge na sociedade atual padronizando comportamentos e práticas sociais, por intermédio de quatros formatos: a razão impotente; a razão arrogante; a razão metonímica e a razão proléptica (SANTOS, 2006).

Dentre os formatos supracitados que se aplica neste estudo, é a razão metonímica, "que se reivindica como a única forma de racionalidade e, por conseguinte, não se aplica a descobrir outros tipos de racionalidade ou, se o faz, fá-lo apenas para torná-las matéria-prima” (SANTOS, 2006, p. 95-96). O que se busca salientar é a tendência que se tem em desprezar as histórias locais como formas de saber, privilegiando histórias hegemônicas que viajam no tempo e no espaço, subalternizando outras culturas.

Santos (2002) ainda considera que a razão indolente como conhecimento hegemônico, seja ele o filosófico ou científico, é o produzido no Ocidente. Portanto, conhecimentos produzidos em outros contextos sociais e culturais são descartados e invisíveis. Segundo Santos (2007, p. 29) "há fabricação de não existência toda vez que uma determinada entidade é desqualificada e tornada invisível, ininteligível ou descartável de uma maneira irreversível”. 
Assim, neste estudo, deve-se considerar que a monocultura do saber formal e do rigor do saber parte da história do Basquetebol americano que se coloca, a princípio, como o único saber válido e rigoroso. Para Santos (2010) essa seria a maneira mais poderosa de fabricação da não existência: Pensamento Abissal ${ }^{1}$.

Essa ótica, por ter como base a transformação da ciência moderna e da alta cultura em critérios únicos de verdade e de qualidade, acaba por excluir qualquer outra forma de prática que não se aproxime de seu modelo. Assim, as práticas sociais cotidianas, aqui denominadas de histórias locais, acabam se tornando invisíveis e consideradas muitas vezes como desprovidas de conhecimentos. Na perspectiva do pensamento hegemônico, as práticas cotidianas tecidas pelos sujeitos em suas culturas são consideradas simplesmente como transmissoras de conhecimentos que lhes são externos.

Portanto, a ciência moderna e a razão indolente assentam no pressuposto de que o conhecimento válido é o conhecimento hegemônico, excluindo ou tornando inexistente a experiência daquele que vivenciou tais acontecimentos, no caso deste estudo as experiências dos jogadores de Basquetebol. Assim, partimos do pressuposto de que o docente não deve ignorar o jogador que vivenciou um episódio, pois o seu relato pode acrescentar múltiplos aspectos de sua forma de perceber a realidade vivida, enriquecendo, com detalhes, a construção dos contextos locais relacionados a determinadas práticas corporais.

O que se procura enfatizar é que sempre se está em busca da informação para se tentar acompanhar a corrida global, a caça incessante pelo que acontece de novo nos quatro cantos do planeta. A informação de ontem é passado, ela tem pouco valor, comparada com aquela que chega no dia de hoje. O mundo leva a se pensar assim: valorizar a nova informação e desprezar aquela que foi passada ontem, mesmo que ela verse sobre o mesmo tema.

E se outros saberes pudessem chegar aos alunos por intermédio das narrativas das pessoas que as vivenciaram? Presenciar-se-ia do outro as suas angústias, alegrias, tristezas e, talvez, a informação perdesse a capacidade de se tornar invisível aos outros conhecimentos? Com relação à informação Benjamin (1994) tece o seguinte comentário:

só tem valor no momento em que é nova. Ela só vive nesse momento, precisa entregar-se inteiramente a ele e sem perda de tempo tem que se explicar nele. Muito diferente é a narrativa. Ela não se entrega. Ela conserva suas forças e depois de muito tempo ainda é capaz de se desenvolver (1994, p. 204).

Aproximar-se da ‘realidade’ vivida pelos “sujeitos ordinários” Certeau (1994), de uma história, esse é o desafio de todos que enveredam pelos caminhos das passagens marcantes. Mas, por mais que se busque informações, sempre faltará uma dose de veracidade dos fatos. Pode-se imaginar como seria esse personagem narrando os capítulos de suas conquistas e dissabores? Ter-se-ia a capacidade de narrar o que melhor lhe aconteceu?

Cada docente deveria percorrer um caminho metodológico procurando se direcionar a partir de uma abordagem pedagógica da Educação Física. Alguns mesclam em suas aulas um conteúdo teórico, enredados por práticas que permitem uma construção pedagógica diferente de docentes que procuram transmitir conhecimentos apenas a partir de aulas expositivas. Outros profissionais ensinam um determinado conteúdo sem estabelecer uma relação com a produção local. A cidade ou região que o profissional atua, pode ter passado ou estar passando por fatos que marcaram ou irão marcar aquela modalidade para sempre. Será que esses acontecimentos não servem de contextualização para a teoria a ser ensinada? Será que o aluno, ao saber de algo que aconteceu ou está acontecendo, almeja participar ativamente e com isso construir a realidade como ser histórico?

1 "Sistema de distinções visíveis e invisíveis, sendo que as invisíveis fundamentam as visíveis. As distinções invisíveis são estabelecidas através de linhas radicais que dividem a realidade social em dois universos distintos: o universo 'deste lado da linha' e o universo 'do outro lado da linha"” (SANTOS, 2007, p. 3). 
Aprender conhecendo a história local pode dar ao discente uma possibilidade de estabelecer aprendizagens significativas, ou seja, construir conexões entre o conteúdo novo e o seu conhecimento prévio sobre o assunto, o que permitiria a apropriação de determinados conteúdos por outros caminhos diferentes da perspectiva mecânica, linear, determinista, bancária (FREIRE, 1987).

No entanto, quando o aprendiz tem pela frente um novo corpo de informações e consegue fazer conexões entre esse material que lhe é apresentado e o seu conhecimento prévio em assuntos correlatos, ele estará construindo significados pessoais para essa informação, transformando-a em conhecimentos, em significados sobre o conteúdo apresentado.

Assim, pensar a partir dos pressupostos estabelecidos por Santos (2002) requer considerar alguns aspectos: primeiramente o desperdício da experiência, que procura contemplar aquelas massacradas pelo domínio do conhecimento científico, onde o mesmo se apropria do que é relevante no momento e exclui outros saberes. No caso deste estudo, a história local, está embasada em acontecimentos do passado, mas que podem ser resgatados e reposicionados adequadamente, para estruturar o que se quer ensinar ou aprender e, principalmente, tendo o cuidado com o presente, para que o mesmo não seja desperdiçado no futuro. O segundo conceito é o do Pensamento Abissal que consiste em entender o motivo da existência de uma linha divisória entre os conhecimentos. O terceiro é o epistemicídio, que o autor descreve como a morte dos conhecimentos alternativos e por último a ecologia dos saberes que visa à possibilidade de que a ciência possa dialogar com os saberes laico, popular, indígena, dentre outros.

De acordo com Santos e Menezes (2010) por diversas vezes, por “ignorância”, não se considera críveis as narrativas e histórias locais construídas ao entorno e que favorecem de alguma maneira, experiências que para a sociedade atual tornam-se inexistentes devido ao imaginário do mundo moderno fabricado pela razão indolente. Para os autores, essa forma de compreensão de mundo divide a realidade a partir de uma linha demarcatória que classifica pessoas, experiências, comunidades e outros. Esse modelo hegemônico entende que:

As distinções invisíveis são estabelecidas através de linhas radicais que dividem a realidade social em dois universos distintos: o universo 'deste lado da linha' e o universo 'do outro lado da linha'. A divisão é tal que 'o outro lado da linha' desaparece enquanto realidade, torna-se inexistente, e é mesmo produzido como inexistente (SANTOS, 2010, p. 32).

Na intenção de contrapor tal imaginário do mundo moderno, os autores propõem a "epistemologia do Sul" que intenciona recuperar os saberes e práticas dos grupos sociais que, por via do capitalismo e do colonialismo, foram histórica e sociologicamente postos na posição de ser tão só objeto ou matéria-prima dos saberes dominantes, considerados os únicos válidos.

Se de um lado da linha demarcatória encontra-se o conhecimento científico estabelecendo julgamento, valores e formas de comportamento, do outro lado, no caso específico deste trabalho, estão as histórias locais, esquecidas ou tornadas inexistentes, desperdiçadas.

Do outro lado da linha, não há conhecimento real; existem crenças, opiniões, magia, idolatria, entendimentos intuitivos ou subjetivos, que, na melhor das hipóteses, podem tornar-se objetos ou matéria-prima para a inquirição científica. Assim, a linha visível que separa a ciência dos seus "outros” modernos está assente na linha abissal invisível que separa de um lado, ciência, filosofia e teologia e, do outro, conhecimentos tornados incomensuráveis e incompreensíveis por não obedecerem, nem aos critérios científicos de verdade, nem aos dos conhecimentos, reconhecidos como alternativos, da filosofia e da teologia (SANTOS, 2010, p.34). 
A ciência ou o conhecimento científico, pautado na perspectiva abissal, procura, especificamente neste trabalho, visibilizar e se apropriar do Basquetebol produzido nos Estados Unidos, como uma forma totalitária da História dessa modalidade esportiva.

Partindo da ótica desse conhecimento - NBA (National Basketball Association - Associação Nacional de Basquetebol) - o único saber validado é o Basquetebol oficial reconhecido pelas Confederações, Federações e Ligas desportivas, portanto, o saber hegemônico como referência. A experiência social em todo o mundo é muito mais ampla e variada do que o que a tradição científica ou filosófica conhece e considera importante (SANTOS; MENEZES, 2010).

O desperdício da experiência está diretamente ligado ao paradigma moderno, que desconsidera os pequenos acontecimentos como fatos importantes e marcantes de uma determinada época.

O conhecimento hegemônico evidencia aquilo que para ele é relevante, que, na sua concepção, tende a ser importante para o mundo. A razão metonímica explica um pouco dessa apropriação. Por achar-se uma única forma de racionalidade e, consequentemente, não se aplicar a novas descobertas, ela se entende como uma única referência.

A razão metonímica deixa uma lacuna ao se pensar que as dicotomias poderiam ser exploradas separadamente, ou seja, falar do homem sem falar da mulher, falar do senhor sem falar do escravo, e porque não, falar das experiências globais estabelecendo relações com as experiências locais. Tal imaginário de mundo emerge de uma concepção do presente que é contraída, precisamente porque a concepção da racionalidade que se possui não permite que se tenha uma visão ampla de nosso presente (SANTOS, 2007).

Ao utilizar o pensamento do referido autor, buscamos compreender e discutir como se encontra a realidade escolar, especificamente na forma com o conteúdo é abordado, constituindo-se como uma totalidade dos conhecimentos disponíveis no mundo.

Hoje a totalidade do conhecimento histórico, específico do Basquetebol, nos remete ao que aconteceu nos Estados Unidos, o país inventor, que é o berço dessa modalidade esportiva no mundo. Mas será que essa totalidade é o suficiente para se ensinar a referida modalidade? Será que essa totalidade não é apenas uma possibilidade de perceber e compreender a história do Basquetebol?

O conteúdo de uma determinada literatura é fruto do saber rigoroso e científico, que utiliza o que é básico para todos, e esse conhecimento básico do Basquetebol, parece ser suficiente para se falar ou pesquisar, principalmente aquele que advém dos Estados Unidos. O que aconteceu ou acontece por lá que demonstra ser interessante para todo o mundo, e com isso passa a ser, para o conhecimento científico, o primordial ou aquilo que é satisfatório para ser passado como ensinamento desta modalidade. No país do Basquetebol é explorado todo e qualquer fato relacionado a esta modalidade, da simples história de vida de uma atleta, até a sua trajetória profissional. As escolas, universidades e franquias, procuram explorar, ao máximo, tudo que envolve tal modalidade esportiva.

Nossa realidade constrói-se de maneira diferenciada quando se procura ensinar uma modalidade e debruça-se sobre o conhecimento científico deixando de privilegiar as práticas sociais que emergem da história local - o Basquetebol da escola (VAGO, 1996; CAPARROZ, 2005).

Estabelecer a mediação com a realidade singular e local permite o diálogo com os conteúdos possibilitando contextualizá-los, enriquecendo o conhecimento como algo significativo, talvez por permitir que o discente se perceba como parte integrante desse processo. Seguindo essa trilha, Vago (1996) comenta que "a escola, como instituição social, pode produzir uma cultura escolar de esporte que, ao invés de reproduzir as práticas de esporte hegemônicas estabeleça” (p. 4) uma relação de tensionamento, propondo uma intervenção na história cultural da sociedade. 
Assim, pensar uma pedagogia do conflito, Santos (1996), requer pensar outras formas de percepção da realidade, buscando diversas metodologias que permitam ao discente construir diferentes processos de aprendizagem, que neste estudo se estabelece a partir das narrativas e das memórias.

Outro aspecto a ser considerado é o conceito de epistemicídio: a morte de conhecimentos alternativos, que descreve a redução que o conhecimento científico estabelece para a realidade vivida por sujeitos ou grupos sociais (SANTOS, 2007, p. 29).

Ao constituir-se como monocultura, destrói outros conhecimentos, produz o que chamo "epistemicídio": a morte de conhecimentos alternativos. Reduz a realidade porque "descredibiliza” não somente os conhecimentos alternativos mas também os povos, os grupos sociais cujas práticas são construídas nesses conhecimentos alternativos.

Santos (2007) busca superar a desinvisibilização das práticas por meio da sociologia das ausências, buscando combater as cinco monoculturas que produzem tais ausências: a do saber e do rigor; do tempo linear; da naturalização das diferenças que ocultam hierarquias; a da escala dominante e a do produtivismo capitalista. Este estudo apropriou-se de duas delas, pois são as que possuem maior articulação com a produção das ausências específicas da pesquisa.

As monoculturas mencionadas são: a do tempo linear e da escala dominante. A primeira procura mostrar que a história só tem sentindo, quando está baseada naquilo que acontece nos países desenvolvidos, ou seja, o que acontece por lá é, definitivamente mais progressista. E a monocultura da escala dominante apoia-se no contexto da existência de um domínio sobre as coisas e é diretamente influenciada pela globalização.

Este contexto permite compreender, como a experiência é desperdiçada pela razão indolente, pois essa racionalidade desconsidera fatos importantes transformando-os em relíquias do passado, em coisas antigas, ultrapassadas, primitivas, sendo, portanto, desprezados como formas de conhecimento, tornando-os inexistentes, e, por não possuírem valor como saber, esses fatos nunca serão credíveis.

Deste modo, torna-se fundamental a experiência no caso deste estudo, da memória do Basquetebol local, que em muitos episódios é excluída do processo, tal como os fatos marcantes que fazem parte da história local, e que hoje estão no esquecimento, e que podem contribuir para a reinvenção (CERTEAU, 1994) do conteúdo a ser ministrado, possibilitando a contextualização de conteúdos no campo da Educação Física escolar.

Essa ideia de que não são críveis gera o que chamo a subtração do presente, porque deixa de fora, como não existente, invisível, “descredibilizada”, muita experiência social. Se queremos inverter essa situação - por meio da Sociologia das Ausências, temos de fazer que o que está ausente esteja presente, que as experiências que já existem mas são invisíveis e não críveis estejam disponíveis; ou seja, transformar os objetos ausentes em objetos presentes (SANTOS, 2007, p. 32).

As novas descobertas podem estar naquilo que já aconteceu e não se sabe ou não se soube explorar, ou seja, não se procurou detalhar fatos marcantes, por, simplesmente, achar suficientes os dados que nos são passados pelas várias ferramentas disponíveis no mundo.

A reflexão é necessária de modo a se levantar problemas e soluções para as lacunas deixadas pela pouca exploração das experiências, sejam essas de uma determinada cultura ou de apenas um sujeito. Quantas passagens marcantes podem ter acontecido dentro de um grupo? Como os sujeitos pertencentes a esses grupos perceberam essa realidade vivida? 
A experiência contextualizada torna-se uma fonte de pesquisa, podendo ser explorada em diversos momentos, evidenciando a experiência local e permitindo apreender as pistas, os indícios, para a percepção de outras possibilidades de se compreender o real (GINZBURG, 1989).

Na intenção de contrapor à razão indolente e ao desperdício das experiências, Santos (2007) propõe a ecologia dos saberes, como uma tentativa de buscar caminhos alternativos para que a ciência deixe de ser uma monocultura e passe a ampliar as suas possibilidades percebendo outros horizontes, procurando explorar outras experiências, dialogando com outros saberes existentes para além dos conhecimentos científicos. Aqui se procura evidenciar o diálogo com a memória e a história local, para que essas passem a ter um espaço dentro do contexto escolar, especificamente na Educação Física e no Basquetebol, no caso deste estudo.

Em relação aos aspectos supracitados, Santos (2007, p. 32) aponta para:

uma ecologia mais ampla de saberes, em que o saber científico possa dialogar com o saber laico, com o saber popular, com o saber dos indígenas, com o saber das populações urbanas marginais, com o saber camponês. Isso não significa que tudo vale o mesmo. Somos contra as hierarquias abstratas de conhecimento, das monoculturas que dizem, por princípio, “a ciência é a única, não há outros saberes”.

Considerando-se o exposto, um dos caminhos a se percorrer é buscar uma posição de destaque para outros saberes, entre eles a memória, que ao sair do anonimato ou do esquecimento, possa ocupar o seu espaço dentro do contexto escolar. Esses saberes, especificamente as histórias locais, podem tornar-se grandes aliados para os temas a serem explorados, proporcionando um entendimento necessário para os alunos e que esses possam enxergar possibilidades de compreender o mundo.

\section{APRESENTAÇÃO E DISCUSSÃO DOS RESULTADOS}

Sabendo que o esporte é constituinte da realidade escolar, ele precisa estar além da prática nas aulas de Educação Física, e deve ser capaz de estabelecer uma ligação significativa com o que o aluno vive em seu cotidiano (ASSIS, 2010). A partir dessa preocupação, buscamos investigar a maneira como os professores de Educação Física desenvolvem os processos de ensino e aprendizagem com o Basquetebol nas escolas.

A primeira pergunta do questionário permitiu a aproximação das práticas docentes e da maneira como os professores concebem a história do Basquetebol. Questionamos os professores se o Basquetebol fazia parte de seu conteúdo durante as aulas de educação física.Ao nos depararmos com a resposta, percebemos que todos os professores entrevistados mencionam a forma como desenvolvem o ensino do Basquetebol.

Esse dado emerge como um indício (GINZBURG, 1989) de que há uma articulação em rede, isto é, um planejamento sistematizado pela rede municipal de ensino de Volta Redonda, que serve como referência para as ações dos docentes deste município. Na intenção de cruzar os dados obtidos com o questionário, buscamos o material utilizado pelos docentes (Concepção e Diretrizes de Educação Física).

O referido documento não se refere ao desenvolvimento do histórico do Basquetebol, as diretrizes que emergem do material privilegia, nos sextos e sétimos anos, a iniciação do esporte por meio de grandes jogos, aprendizado dos fundamentos e regras básicas. Em relação aos oitavos e aos nonos anos propõe uma revisão dos fundamentos e regras e o desenvolvimento dos sistemas táticos. Diante do exposto, e tendo como referência a abordagem Crítico Superadora, percebemos que a rede municipal, por meio das diretrizes e das ações dos professores, não busca discutir e problematizar as questões que influenciou o processo histórico da referida modalidade. 
Com relação aos aspectos históricos a pesquisa nos revelou pistas significativas (GINZBURG, 1989) em relação ao disposto nos parágrafos anteriores: É importante evidenciar que dos trinta e dois professores entrevistados, três professores disseram que não seria possível ensinar o Basquetebol a partir da história local. No entanto, é preciso problematizar tais respostas, pois quando solicitados a justificar, os professores relataram o seu posicionamento da seguinte forma:

$\underline{\text { O Professor } 1}$ relata que a história do esporte extrapola os limites de uma história regional, porém essa história não deve ser renegada como parte do conteúdo.

$\underline{\text { O Professor } 2}$ relata a falta de conhecimento sobre o assunto para ensinar.

$\underline{\text { O Professor } 5}$ relata a dificuldade em encontrar material didático referente ao assunto.

Ao olhar atentamente a resposta do professor 1, percebemos que o docente não nega a possibilidade do trabalho utilizando os conhecimentos locais do referido esporte, mas considera a necessidade de relacionar as demandas locais ao que ocorre no espaço global, o que nos remete à percepção da tentativa de contextualização dos conteúdos.

O Coletivo de Autores (1992, p. 19) menciona a necessidade de alguns princípios para o tratamento do conteúdo. Os dados que emergem da fala do professor 1 se aproxima do princípio da "relevância social do conteúdo”. Este princípio atua na tentativa de auxiliar o educando a compreender o sentido e o significado do conteúdo desenvolvido. Para os autores o conteúdo ministrado deve estar articulado "à explicação da realidade social concreta e oferecer subsídios para a compreensão dos determinantes sócio-históricos do aluno, particularmente a sua condição de classe social”.

Portanto, se o professor pretende contextualizar os seus conteúdos e permitir que o educando compreenda os condicionantes que emergem com a cultura corporal em que está imerso, não deve desconsiderar os aspectos históricos em tais práticas forjadas.

Com relação aos docentes 2 e 5, o depoimento remete a pensar que tais professores se aproximam de abordagens que desconsideram o contexto histórico das práticas corporais de seus alunos. Até que ponto os referidos docentes utilizam a tendência Competitivista? Será que os professores privilegiam a técnica e a competição como finalidades?

Com relação aos docentes que justificaram a sua resposta, é relevante salientar que, percebemos uma aproximação com o que o Coletivo de Autores (1992, p. 39) considera relevante ao desenvolver uma ação pedagógica: "É fundamental para essa perspectiva da prática pedagógica da Educação Física o desenvolvimento da noção de historicidade da cultura corporal”.

Na tentativa de problematizar os dados empíricos da pesquisa, gostaríamos de retomar a discussão sobre ensinar o esporte utilizando dados referentes a história local. A razão de reiniciar tal debate se deve ao exposto pelos docentes em outras questões da pesquisa: o professor 2 menciona "a falta de conhecimento sobre o assunto para ensinar". A resposta do docente permite compreender algumas dificuldades enfrentadas pelos profissionais de Educação Física, pois nem todos possuem conhecimentos históricos (locais) da modalidade ensinada. Esse dado é revelador e nos permite perceber a necessidade de pesquisas históricas, na ordem da micro-história (REVEL, 1998), na tentativa de produção de material pedagógico que auxilie os processos de ensino e aprendizagem.

A narrativa do professor 5 também evidencia e justifica a situação-problema que emerge da discussão supracitada, a fabricação de material didático, pois o docente relata que o problema de se incluir, no conteúdo da Educação Física, a história local, está diretamente ligado "à dificuldade em encontrar o material didático referente ao assunto". 
Com relação a questão supracitada, é importante esclarecer que os outros trinta professores não se posicionaram em relação à dificuldade de desenvolver ações pedagógicas a partir da história local.

Considerando as respostas explicitadas, é relevante ressaltar que apenas um dos entrevistados não considerou importante a abordagem do esporte articulada a história local em suas aulas (professor 4). Dessa forma cabe perguntar: Até que ponto esse professor se utiliza do esporte na perspectiva tecnicista em suas aulas?

No entanto, a resposta do docente nos remete a uma contradição em suas narrativas, pois ao ser questionado sobre a possibilidade de ensinar o Basquetebol por meio da história local, o professor menciona a necessidade de contextualizar conteúdos ensinados na Educação Física e, que, a história local, independente de sua origem, ela é base para os conhecimentos atuais.

A ambiguidade revelada na narrativa do professor remete a duas questões centrais: o distanciamento entre teoria e prática e o desconhecimento sobre os pressupostos teóricos da abordagem Crítico Superadora.

Com relação ao distanciamento entre a teoria e a prática é importante esclarecer que o fato de ler ou estudar tal teoria não implica em uma compreensão de como se desenvolve a sua metodologia ou implementação no chão da escola. Isso leva à segunda questão, um possível desconhecimento dos pressupostos teóricos da abordagem Crítico Superadora.

O docente que atua na perspectiva da Cultura Corporal deve entender que os conteúdos abordados em aula, emergem das demandas sociais que impactam a realidade em que a comunidade escolar está inserida, portanto, o diagnóstico, conforme já exposto neste trabalho, é elemento fundamental no planejamento pedagógico e, em decorrência, da Educação Física.

Partindo desse pressuposto, deve-se salientar que, a partir da compreensão da realidade local, e da materialidade histórica que a compõe, o docente estabelece o seu processo de intervenção (teleologia), o seu planejamento. Para o Coletivo de Autores (1992, p. 40), “essa visão de historicidade tem um objetivo: a compreensão de que a produção humana é histórica, inesgotável e provisória”.

Assim, não se quer aqui julgar a posição do docente, mas realizar o movimento de problematização do seu ponto de vista para daí pensar em um processo de intervenção, a problematização, a nível local, das práticas corporais experienciadas na escola.

Outro aspecto importante a ser ressaltado, foi questionamento realizado aos docentes sobre a inserção da história local do basquetebol nos conteúdos da disciplina Educação Física, que emerge nos depoimentos de dezesseis professores, dos quais apresento trêscomo exemplos lapidares:

Professor 3: É importante ensinar o passado da modalidade, pois os alunos enriquecerão sua cultura e poderão sentir cada vez mais orgulho em morar na sua cidade. Além de entender o presente, baseado nas dificuldades do passado.

Professor 4: A contextualização dos conteúdos ensinados pela Educação Física na escola é um dos pressupostos para uma educação de qualidade. É importantíssimo acontecer um esclarecimento maior sobre a cultura esportiva da região, de modo a levar os alunos a identificarem-se com a mesma. A história local, independente de sua origem, ela é base para os conhecimentos atuais.

Professor 7: O resgate da história local deve estar mais próximo possível da realidade social dos alunos. 
Professor 25: A motivação será maior, considerando a possibilidade, inclusive, da presença de ex-jogadores ainda vivos e morando em Volta Redonda.

É importante que se perceba que o Coletivo de Autores (1992) defende a ideia de que a escola deve priorizar as discussões e os processos de ensino e aprendizagem pautados na relação sentido e significado na tentativa de permitir ao discente uma análise crítica dos conteúdos ministrados, em vez da uma aprendizagem mecânica do ensino tradicional.

Assim, os relatos dos professores supracitados se aproximam da ótica superadora, que permite ao docente utilizar as temáticas e os problemas locais como ponto de partida para a discussão de problemas socias, políticos e econômicos.

Outro aspecto relevante mencionado pelos docentes, e que é tema central deste estudo, está evidenciado nas justificativas de alguns professores quando esses demonstram a existência de uma preocupação com o resgate da história local.

Não se pode deixar de refletir sobre o fato de que alguns profissionais não apresentaram justificativas, o que limitaa compreensão da sua forma de pensar e agir no que se refere ao trato com suas experiências no cotidiano escolar. O silêncio evidenciado nas justificativas causa impressão de que alguns profissionais compreendem a realidade apenas a partir de um único prisma, o conhecimento hegemônico. O esporte hegemônico é a técnica do movimento transparecendo ser a única forma de conteúdo para as aulas (SANTOS, 2002).

Nesse sentido, Santos (2002) entende que o paradigma dominante, por intermédio da razão indolente, monocultural, não considera credível outras formas de conhecimentos, como por exemplo: o senso comum e os estudos humanísticos (históricos, jurídicos, literários, filosóficos e teleológicos), e em relação à pesquisa o conhecimento local.

Outro dado da pesquisa que consideramos relevante, foi o questionamento aos docentes sobre a fase do ensino em quea história do Basquete deveria ser desenvolvido. Doze professores mencionaram que o conteúdo deveria ser desenvolvido no sexto ou sétimo ano do Ensino Fundamental; Dez professores responderam que o Basquetebol deveria ser o conteúdo do oitavo ou nono ano; E, dez professores consideraram apropriado que tal aprendizagem fosse efetuada no Ensino Médio.

Diante da diversidade das respostas apresentadas cabe o seguinte questionamento: até que ponto os docentes consideram o planejamento estabelecido pela SME-VR? Se discordam de tal planejamento, qual a abordagem pedagógica utilizada pelos docentes para referendar a sua ação pedagógica?

O que se busca refletir, diante dos dados apresentados, caminha na seguinte direção: a primeira dialoga com as diretrizes da rede municipal (SME-VR Secretaria Municipal de Educação de Volta Redonda) e a segunda com uma possível abordagem do campo da Educação Física.

Com relação à primeira direção, ao investigar o documento da SME-VR que direciona as ações curriculares, nos deparamos com a sugestão de uma abordagemsobre as regras, fundamentos e sistemas táticos do Basquetebol, para os anos finais do ensino fundamental. É necessário frisar, que na rede municipal, a Educação Física não atua nos anos iniciais do Ensino Fundamental.

Outro aspecto relevante é o fato de que o documento não sugere a abordagem do processo histórico. No entanto, cabe ressaltar a contradição do documento, pois apresenta uma proposta citando que: 
A Educação Física não é um conhecimento que se possa incorporar dissociado de uma vivência concreta, não pode transformar-se num discurso sobre a cultura corporal do movimento, sob a pena de perder a riqueza de sua especificidade, mas deve constituir-se como uma ação pedagógica que será sempre uma vivência impregnada da corporeidade do sentir e do relacionar-se (SME, 2013, p. 1).

Sabendo que a corporeidade perpassa por um processo singular do ser humano e, que se constitui na tessitura do passado (história de vida), do presente (momento atual) e do devir (aquilo que o sujeito pensa em relação ao seu futuro) (FREITAS, 1999), percebemos uma contradição ao constatar que o documento não privilegia a história do Basquetebol, desconsiderando a base do que apresenta em sua proposta filosófica (Cultura Corporal e Corporeidade).

Outra parte do documento permite que se perceba a contradição já mencionada, é quando se refere ao conteúdo conceitual:

A Educação Física deve levar o aluno a descobrir motivos e sentidos nas práticas corporais, favorecer o desenvolvimento de atitudes positivas para com elas levar a aprendizagem de comportamentos adequados a sua prática, levar ao conhecimento, compreensão, e análise do seu intelecto os dados científicos e filosóficos relacionados à cultura corporal de movimento, dirigir sua vontade e sua emoção para a prática e a apreciação do corpo em movimento (SME, 2013, p. 2).

Segundo o Coletivo de Autores (1992, p. 25) o caráter histórico é fundamental para que se compreenda o processo teleológico - "porque determina o alvo onde se quer chegar" - permitindo ao aluno desenvolver, em face de seu passado, de suas representações, de sua corporeidade, desenvolva suas significações objetivas, o seu sentido pessoal e coletivo.

Outro aspecto que consideramos relevante problematizar é o fato de dez docentes assinalarem o Ensino Médio, como a fase em que ensinam a história do Basquetebol. Questionamos este posicionamento: qual o critério utilizado para que somente nesta fase a história da referida modalidade fosse desenvolvida?

O Coletivo de Autores (1992, p. 30) apresenta uma proposta de apropriação do conhecimento seguindo o princípio da espiralidade, para melhor compreender e incorporar os conteúdos ensinados. A obra citada concebe esse princípio da seguinte forma: "Significa compreender as diferentes formas de organizar as referências do pensamento sobre o conhecimento para ampliá-las”. Pensar o currículo a partir dessa referência nos permite perceber que há uma sequência do conhecimento ou ordenação do pensamento.

Esse conceito apreende que há uma ampliação do conhecimento a cada ciclo de ensino e ao se chegar no $4^{\circ}$ ciclo, é o momento de aprofundamento da sistematização do conhecimento, onde o aluno deve ser incentivado à pesquisa, adquirindo uma condição de produtor de conhecimentos científicos. A escola deve ter a intenção de: "formar um cidadão crítico e consciente da realidade social em que vive, para poder nela intervir na direção dos seus interesses de classe” (COLETIVO DE AUTORES, 1992, p.36).

Esses profissionais evidenciam a possibilidade, de que a apropriação do conhecimento da história do Basquetebol é mais bem absorvida pela fase que compreende o $4^{\circ}$ ciclo (Ensino Médio). Questionamos essa perspectiva por percebemos que a história auxilia o processo de compreensão da realidade, necessitando, portanto, de acordo com cada ciclo, a adaptação do conteúdo à realidade cognitiva do aluno.

O planejamento dessa sistematização precisa ser repensado, de modo que o aluno receba a cada ciclo um conhecimento mais aprofundado do conteúdo, ampliando com isso sua visão de mundo.

A Pedagogia Crítico Superadora proposta por este estudo, como forma de contribuição para o ensino da Educação Física, evidencia que essa disciplina precisa ser apoiada pela escola, com ações que possam executar uma triagem de conteúdos a serem ensinados, para um eficiente trato com temas da cultura corporal. 


\section{CONSIDERAÇÕES FINAIS}

O artigo ora apresentado buscou compreender os pressupostos teóricos da racionalidade moderna e as consequências no ensino da Educação Física Escolar, mais especificamente do ensino do Basquetebol na rede municipal de Volta Redonda.

Inicialmente nos debruçamos no que Santos (2002) denomina como desperdício da experiência e suas consequências no ensino da história do Basquetebol. Como o estudo trata da história local, nos resultados apresentados, nos deparamos com informações e relatos que afirmam a invisibilidade imposta aos sujeitos e suas experiências dentro da referida modalidade.

Parece-nos que para a ciência moderna (razão indolente), a história do Basquetebol de Volta Redonda não existe, pois ela não pertence ao conhecimento hegemônico. Esta imposição ignora o que foi vivido pelos sujeitos, a contribuição das narrativas e imagens para o processo de aprendizagem e, acima de tudo, ignora os acontecimentos que fizeram parte da construção desta história local.

Na tentativa de contribuir com a superação da razão indolente e ao desperdício da experiência, buscamos visibilizar as consequências de tal pensamento nas práticas docentes, na intenção de provocar uma ruptura na barreira imposta pelo conhecimento hegemônico. A inserção, no processo de ensino e aprendizagem, de outras informações referentes ao Basquetebol pode proporcionar outro entendimento sobre como o docente ensina a referida modalidade e como propõe o desenvolvimento da prática do Basquetebol.

Os resultados apresentados no questionário aplicado aos profissionais de Educação Física demonstraram, que alguns só ensinam o que o conhecimento hegemônico proporciona. Eles justificam este posicionamento metodológico apontando para alguns fatores como a falta de conhecimento da modalidade ou a ausência de literaturas com informações mais específicas.

Diante do exposto, o ensino do Basquetebol, nas escolas de Volta Redonda, pode ter um maior significado se for inserido o que esta modalidade apresenta de história a nível local. Os alunos poderiam desfrutar do que ocorreu no passado e estes acontecimentos serviriam de incentivo para possíveis práticas em suas vidas.

Neste sentido, uma contribuição para esta problemática, pode ser a inclusão da história local nos conteúdos de Educação Física, tornando as aulas mais significativas, por dialogar com o espaço em que estão inseridos. Já os alunos poderiam mergulhar nas histórias de vida de personagens, que pertenceram à construção da memória dessa modalidade esportiva, no espaço onde vivem, na intenção de dar sentido à prática corporal vivenciada.

Assim, a relação com as memórias e experiências pode dar outro significado no processo de ensino e aprendizagem do Basquetebol, permitindo a reinvenção do esporte no cotidiano das escolas. Contextualizar o ensino tornando-o significativo, por meio da história local, acrescenta sentido na vida do aluno e passa a ser uma estratégia metodológica, pois as singularidades da escola e da região passam a ser o ponto de partida para futuras reflexões com outros aspectos de ordem global.

Por fim, o estudo revela dados que confirmam as dificuldades encontradas pelos professores para contextualizar tais práticas corporais, tornando visíveis as estratégias de alguns docentes: a transmissão do conhecimento hegemônico. Em contrapartida, surgiram aqueles que entendem a importância de se resgatar a história local, mas esbarram na falta de um material didático.

Isto nos leva a perceber que existe a necessidade da produção de pesquisas e materiais didáticos, que busquem romper com a barreira do conhecimento hegemônico e paralelamente visibilizar sujeitos e acontecimentos do Basquetebol de Volta Redonda e demais localidades, propondo novas formas de ensinar a referida modalidade esportiva. 


\section{REFERÊNCIAS}

ASSIS, de Oliveira, Sávio. Reinventando o esporte: possibilidades da prática pedagógica - 3. ed. Campinas, SP: Autores Associados, chancela editorial CBDE, 2010.

BENJAMIN, Walter. Magia e técnica, arte e política: ensaios sobre literatura e história da cultura. 7 ed. São Paulo: Brasiliense,1994.

BETTI, M; ZULIANI, L. R. Educação Física Escolar: uma proposta de diretrizes pedagógicas. Revista Mackenzie de Educação Física e Esporte - 2002, 1(1): 73-81.

CAPARROZ, Francisco Eduardo. Entre a Educação Física na escola e a Educação Física da escola: a Educação Física como componente curricular, 2 ${ }^{\mathrm{a}}$ Edição -Campinas: Autores Associados, 2005.

CASTELLANI FILHO, Lino. Educação Física no Brasil: a história que não se conta. 19 ed. São Paulo: Papirus Editora, 2011.

CERTEAU. Michel. A invenção do cotidiano: 1. Artes de fazer. Petrópolis: Vozes, 1994.

CERVO, Amado Luiz; BERVIAN, Pedro Alcino. Metodologia Científica 5a Edição - São Paulo: Prentice Hall, 2002.

COLETIVO DE AUTORES. Metodologia do Ensino de Educação Física. São Paulo: Cortez, 1992.

DOMINICÉ, P. O processo de formação e alguns dos seus componentes relacionais. In: NÓVOA, A.; FINGER, M. (Org.). O método auto(biográfico) e a formação. Natal: EDUFRN, 2010 - p. 83-95.

FREIRE, Paulo. Pedagogia do oprimido, $17^{\text {a }}$ Ed. Rio de Janeiro, Paz e Terra,1987.

FREITAS, H.C.L. A reforma universitária no campo da formação dos profissionais da educação básica: as políticas educacionais e o movimento dos educadores. Educ. Soc., Campinas, v. 20, n. 68, dez. 1999.

GIL, Antonio Carlos. Como elaborar projetos de pesquisa. 4. ed. São Paulo: Atlas, 2008.

GINZBURG, C. Mitos, Emblemas e Sinais: Morfologia e História. Tradução Federico Corotti. São Paulo: Cia das Letras, 1989.

MINAYO, Maria Cecília de Souza. O desafio do conhecimento: pesquisa qualitativa em saúde. 12.ed. - São Paulo: Hucitec, 2010.

MEIHY, José Carlos S. B. Manual de história oral. São Paulo: Loyola, 2005.

REVEL, Jacques. (org.). Jogos de escalas:A experiência da microanálise. Rio de Janeiro: FGV, 1998.

SANTOS, Boaventura de Sousa. Para um novo senso comum: a ciência, o direito e a política na transição paradigmática. 4ed, - São Paulo: Cortez, 2002.

Renovar a teoria critica e reinventar a emancipação social. São Paulo: Boitempo, 2007.

Conhecimento prudente para uma vida decente: “um discurso sobre as ciências" revisitado. 2 ed. São Paulo: Cortez, 2006.

SANTOS, Boaventura de Sousa; MENEZES, Maria Paula (orgs.). Epistemologias do Sul. São Paulo: Cortez 2010.

VAGO, T. M. O“esporte na escola” e o "esporte da escola”: da negação radical para uma relação de tensão permanente: Um diálogo com Valter Bracht. Movimento, v.3, n. 5, p. 4-17, 1996.

VAGO, Tarcísio Mauro. Pensar a educação física na escola: para uma formação cultural da infância e da juventude. Cadernos de Formação RBCE, v. 1, n. 1, 2009. 